\title{
Role of Pulse Oximetry Screening for Detection of Life Threatening Congenital Heart Detects in Newborn
}

\author{
Aso Faeq Salih \\ Pediatric Department \\ College of Medicine \\ University of Sulaimani \\ Sulaimani, Iraq \\ aso.salih@univsul.edu.iq
}

\author{
Adnan Mohammed Hamawand \\ Pediatric Department \\ College of Medicine \\ University of Sulaimani \\ Sulaimani, Iraq \\ adnan_alhamwandi@yahoo.co.uk
}

\author{
Riyadh AbdAljabbar Sattar \\ Pediatric Department \\ Pediatric Teaching Hospital \\ Ministry of Health \\ Sulaimani, Iraq \\ riyadhjabbar@yahoo.com
}

\begin{abstract}
Most of newborns with Congenital Heart Defects (CHDs) can be detected by using echocardiography. However, if such defects are not diagnosed in earlier time, therefore a severe hypoxemia, shock, acidosis and death are considered of some potential sequelae. A prospective study from January 2012 to the end of 2013 was performed and 2181 neonates were enrolled in the study. The pulse oximetry screening (POS) for both hands and one foot were obtained within the first 3-6 hours of life, when post ductal saturation was below $90 \%$, it was considered as a positive screening, while when the saturation is between 90-95\% and the difference between pre-and post-ductal saturation was more than $3 \%$, the baby was provisionally considered to be screening as a positive then echocardiography is planned. Among 100 positive POS babies, 45 (45\%) of them were detected with $\mathrm{CHS}$, 12 (12\%) was with a major CHS and 33 (33\%) was with a minor CHS. Out of 12 patients with a major CHD 6 of them (50\%) were asymptomatic at the time of POS.POS result was a true negative in 2078 patients, a true positive in 45 patients, false negative in 3 patients, and false positive in 55 and 28/55 of the false positive rate with POS had other pathology. The false positive rate with pulse oximetry screening is $(55 / 2081)=0.26 \%$. Sensitivity, specificity, positive and negative predictive value for POS in detection of major CHD were $80 \%$, $\mathbf{9 7 . 2 9 \% , 1 7 . 9 \%}$ and $\mathbf{9 9 . 8 0 \%}$, respectively. Pulse oximetry screening is significantly improving the detection of life threatening congenital heart disease at an early stage.
\end{abstract}

Keywords: Pediatrics, Pulse Oximetry, Congenital Heart Defects, Newborn.

\section{INTRODUCTION}

Congenital heart defect with a critical lesion is considered to be at risk of acute cardiovascular collapse or death. At least 18 distinct types of CHD are recognized, with many anatomical variations [1]. Most of newborns with CHD can be diagnosed using echocardiography, However, if such defects are not diagnosed in earlier time, therefore a severe hypoxemia, shock, acidosis and death are considered of come potential sequelae. Timely recognition of these conditions is likely to improve outcome and therefore the evaluation of screening strategies to enhance early detection is of importance [6]. Major CHDs are usually resulted in death or required an invasive intervention therapy such as surgery or cardiac catheterization during the infancy period, in which the earlier detection by screening is the most important and likely to be improved outcome. We have further divided this group into two subcategories: critical and serious. Critical lesions are most likely to present in the first few days or weeks of life, usually as a result of closure of the ductus arteriosus [8]. Wren et al are described critical CHDs in their study in the accordance with a previously published UK categorization to include all potentially life-threatening duct-dependent conditions in addition to infants dying or undergoing invasive procedures such as surgery or cardiac catheterization within the first 28 days of life, although it is accepted that the death from undiagnosed CHDs can occur after that age. Serious CHDs are defined as those defects are not classified as a critical that result in death or invasive intervention within 12 months of age [2].

The prevalence of major defects remains essentially unchanged at around 2.5 per 1000 live births $[1,4,8]$. Critical lesions have an estimated incidence of $1-1.8$ per 1000 live births $[2,9,10]$ and this group accounts for between $15 \%$ and $25 \%$ of all CHDs, depending on the definitions used [2,7]. Most of life-threatening and critical CHDs Importantly life-threatening, critical are asymptomatic at birth and in whom deterioration or death can occur before the condition is diagnosed [11]. Echocardiography is considered that it has significant limitations in term of a screening tool due to its high false positive (FP) rate. Moreover, it is due to the cost and a lack of availability of trained personnel for examination performance [3,7].

Generally, the rationale for pulse oximetry screening is usually depended on the presence of hypoxaemia to some degree in the majority of CHDs. This may result in the 
obvious cyanosis. However, a mild degree of hypoxaemiais very difficult be detected by clinical observation and even though by experienced clinicians [13]. The difficulty is exacerbated in infants with pigmented skin [14]. These results have an important role in exploration the possibility of pulse oximetry, which might be useful in detection of hypoxaemia associated with CHDs in apparently healthy newborns. Furthermore, a number of studies have been published that applied pulse oximetry as a screen for CHDs in this group $[1017,26]$.

\section{METHODS AND MATERIALS}

Prospective study included babies born at maternity hospital in Sulaimani and babies born in private hospitals and referred to pediatric neonatal care unit in the first day of life for optimizing screening performance with pulse oximetry. The study period was from 1 October 2012 to 1 march 2013. During that period, 2371 live babies born. Out of these new born babies 2181 were enrolled in the study. The remaining newborns were excluded because they were premature. Pulse oximeter screening was performed using B3-GIMA portable pulse oximeter with a neonatal OxiMax adhesive sensor. The accuracy of $\pm 2 \%$ for the measurement of oxygen saturation (SpO2) is applied by the manufacturer. Two dimensional and Doppler (spectral and color) echocardiography examinations were obtained by same operator for positive screening patient using a commercial instrument with 3VC and 7VC MHz transducers (adjusted according to patient chest wall thickness) Acusons Cypress, USA made, supplied by Siemens company.

The POS for both hands and one foot were obtained within the first 3-6 hours of life. Probe will be fixed on the wrist or palm and to the sole of the foot, by a random order. The same oximeter was used for all three sequential measurements. In order to have less movement artifacts, the pulse was watched until a good waveform was observed. It usually required 3-5 minutes for all 3 measurements to be performed. The parents were informed, but no written consent was obtained on enrolment in the study, the following information of each infant was recorded: Gestational age, age at echocardiography done, sex, birth weight, way of delivery, Apgar score at 5 minutes, any association like IDM, IUGR, trisomy and any associated clinical presentation like murmur, cyanosis, tachypnea, apnea and grunting.

When post ductal saturation was below $90 \%$ it was considered as positive screening while saturation between 90-95\% and the difference between pre-and post-ductal saturation more than $3 \%$ the neonate regarded previously to be screening positive, but the measurement should be repeated. After three repeated positive finding, they were arranged to have an echocardiogram performed on the same day according to the study protocol. When oxygen saturation above $95 \%$ is define as normal and no further action is done. This protocol is shown on figure 1 below. POS results were recorded and statistics were performed on the data using SPSS 17, version for Windows.

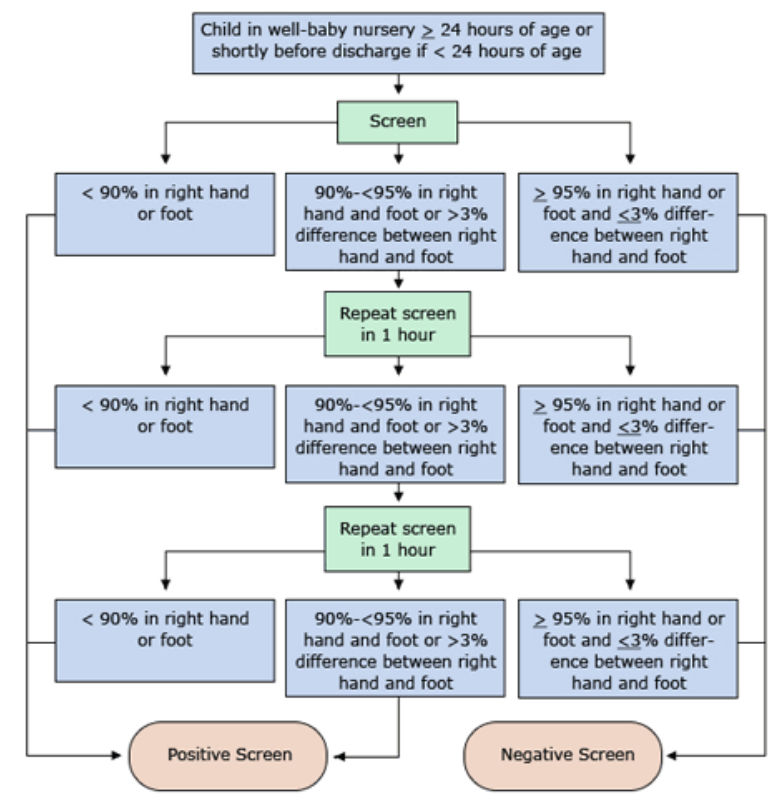

Figure 1: Algorithm for pulse oximetry screening for CHD [27].

\section{RESULTS}

During the study period of five months, data from 100 babies with positive POS were recorded and analyzed. The median age at the time of echocardiography was (12 hours range from 1-3 days). Table 1summarizes the baseline demographic characteristics of the study population.

Table 1: baseline characteristic of study population.

\begin{tabular}{|c|c|}
\hline Variable & No. \\
\hline \multicolumn{2}{|l|}{ Gestationsl age } \\
\hline Full term & $92(92 \%)$ \\
\hline Post term & $8(8 \%)$ \\
\hline \multicolumn{2}{|l|}{ Gender } \\
\hline Make & $47(47 \%)$ \\
\hline Female & $53(53 \%)$ \\
\hline \multicolumn{2}{|l|}{ Apgar score at 5 minnte } \\
\hline Below 7 & $21(21 \%)$ \\
\hline Above 7 & $79(79 \%)$ \\
\hline \multicolumn{2}{|l|}{ Mode of delivery } \\
\hline$d \mathbf{s}$ & $59(59 \%)$ \\
\hline NVD & $41(41 \%)$ \\
\hline Fanily history of CHD & $4(4 \%)$ \\
\hline \multicolumn{2}{|l|}{ Age at Echo done: } \\
\hline Before 24 hour & $67(67 \%)$ \\
\hline After 24 hour & $33(33 \%)$ \\
\hline Antenatal diagnosis & 0 \\
\hline IDM & $9(9 \%)$ \\
\hline Trisomy & $8(8 \%)$ \\
\hline IUGR & $10(10 \%)$ \\
\hline
\end{tabular}


ACHD was detected in 45 babies (45\%) 12 babies were classified as major CHD and 33 babies (33\%) as minor CHD. An overview of the echocardiographic findings in the 100 screening-positive patients is given in (Figure 2), and the diagnoses are listed in (Table 2).

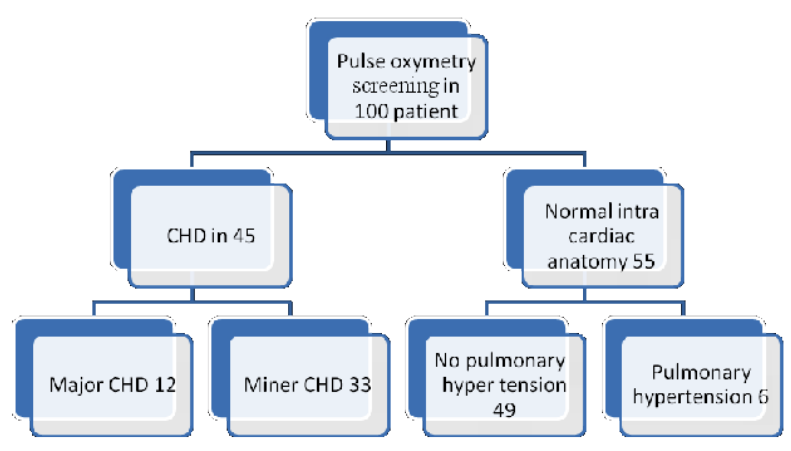

Figure 2: Echo graphic finding in 100 patients with positive oximetry screening.

Table 2: Types of congenital heart disease detected by pulse oximetry screening.

\begin{tabular}{lc}
\hline Group of diagnosis & N \\
\hline Major CHD & 12 \\
TGA & 2 \\
TOF & 2 \\
TA & 1 \\
HLHS & 1 \\
PA & 2 \\
AVSD & 2 \\
COA & 2 \\
Minor CHD & 33 \\
Isolated PDA * & 5 \\
Non isolated PDA ** & 8 \\
VSD & 8 \\
ASD & 10 \\
PS & 2 \\
\hline * Isolated PDA means PDA without other CHD. \\
** non isolated with PDA: means associated with ASD in 5 patient \\
and VSD in 4 patients.
\end{tabular}

There was extra clinical finding that make a decision for echocardiography among 19/45 patients: murmur (8), blue discoloration (10), Trisomy (8).

A separate analysis was performed for the 12 patients with major CHD (Table 3), 6 of these 12 patients (50\%) were asymptomatic at the time of POS.
Table 3: Clinical findings in patients with major congenital heart defects $(n=12)$.

\begin{tabular}{|c|c|c|c|c|}
\hline cyanosis & Heart marm & Asymptomatic & N & Major CHI \\
\hline 1 & 0 & $1(50 \%)$ & 2 & TGA \\
\hline 0 & 1 & $1(50 \%)$ & 2 & TOF \\
\hline 0 & 0 & $1(100 \%)$ & 1 & $\begin{array}{c}\text { Tricuspid } \\
\text { atresia }\end{array}$ \\
\hline 0 & 1 & 0 & 1 & HLHS \\
\hline 2 & 0 & 0 & 2 & $\begin{array}{c}\text { Pulmonary } \\
\text { atresia }\end{array}$ \\
\hline 0 & 0 & $2(100 \%)$ & 2 & AVSD \\
\hline 1 & 1 & $1(50 \%)$ & 2 & COA \\
\hline & & $6(50 \%)$ & 12 & Totsl \\
\hline
\end{tabular}

POS was true negative in 2078, true positive in 45 patients, false negative in 3 patients, (TA in 1 patient, PDA in 1 patient and isolated VSD in 1 patient) and false positive in 55 .

POS was false-positive related to the diagnosis of CHD in 55 newborns (healthy $n=27$, persistent pulmonary hypertension of the newborn $n=6$, sepsis $n=13$, RDS $=4$, birth asphyxia =5). And false positive rate with pulse oximetry screening is $(55 / 2081)=2,6 \%$. A positive pulse oximetry screening gives a $(\mathrm{P}=0.003)$ of having major congenital heart disease. The specificity, sensitivity, positive predictive value, and negative predictive value of pulse oximetry screening for major CHD were shown in (Table 4).

Table 4: The performance of screening methods in the detection of major congenital heart disease in newborn infants.

\begin{tabular}{ll}
\hline \multicolumn{1}{c}{ Performance } & pulse oximetry \\
\hline & \\
\hline Sensitivity & $80 \%$ \\
Specificity & $97.29 \%$ \\
Positive predictive vahue & $17.9 \%$ \\
Negative predictive value & $99.80 \%$ \\
False-positive rate (\%) & $2.6 \%$ \\
No of true positives & 12 (major CHD) \\
No of false negatives & 3 \\
No of false positives & 55 \\
No of true negatives & 2078 \\
\hline
\end{tabular}

\section{DISCUSSION}

Due to the published statistical data, about 0.8-1 babies per 1000 live births are at risk for life threatening cardiac malformation and $30 \%$ of such infants either are leaving hospital without the detection of malformation or return to hospital in a circulatory collapse or die at home [20]. An instant trial for early detection of such disorders was performed.

The current investigation demonstrates that over a period of 5 months' age; POS is allowed the early detection of CHD in 45 neonates, including12 neonates with a major CHD. The list of detected asymptomatic major CHD in this study is mainly interested and also includes acyanotic 
lesions such as coarctation of the aorta and atrioventricular septal defect (Table 4). One of the asymptomatic cyanotic CHD in our study was TA with ASD and VSD, oxygen saturation was below 90\% several hours after birth and echocardiography done at the same time. Although in TA, there is some degree of cyanosis at birth, but here the cyanosis was not so evident, probably due to the associated shunt (PDA).

The normal course of postnatal oxygen saturation is well known [16]: a healthy newborn at the age of two minutes has a mean arterial oxygen saturation of $73 \%$, which rises to $95 \%$ within one hour. This process is mainly individually and considerably being varies, which explains the high rate of false positive POS test results in investigation with screenings very soon after birth $[12,28]$.

In the current study population, (55\%)of patients were recorded with a low saturation (positive POS) and had a normal intracardiac anatomy. Pulmonary hypertension accounts for at least $10.9 \%$ of these false positive test results in our study. The early diagnosis of persistent pulmonary hypertension in neonates is considered to be beneficial, which is including in the absence of CHD, since it can be drawn the attention to an underlying problem such a sepsis.

Many previously published studies try to assess the applicability of pulse oximetry screening for congenital heart disease and the study populations ranged from (2114 to 11281) to enable a confident estimate of sensitivity, as there are no ascertainment of missed cases dying in the community that made unsupported claims of sensitivity $[10,18,19,20.26 .29]$ since Wren et al. showed that an average of $5 \%$ of all babies with critical heart disease died undiagnosed in the community [2].

Upon the cut-off criteria in these studies, the false positive rate of pulse oximetry screening varied between $0.009 \%$ and $5 \%$. Richmond et al. showed that the introducing of repeat pulse oximetry brought their false positive rate down from $5 \%$ to $1 \%$ [10].

In our study, the sensitivity of POS for detection of CHD was $80 \%$, and the rate of false positive result of POS was relatively high (2.6\%), the reason for a high false result, it may be due to the time of screening of POS soon after birth and experience of doctor taking the measure, also the current investigation sample size is relatively small in comparison to other studies.

In Balu V et al shows poor sensitivity of POS (19\%) [30] in comparison with clinical examination which was much higher than POS and shows high false positive rate in comparison to our study.

In Balu V et al study they thought that this low result may be due to the fact that only four patients in their study had critical CHD. In addition, technical and human factors may also have contributed to the low sensitivity of pulse oximetry, Hence, repeated testing and adequate training of manpower is required before pulse oximetry can be recommended for clinical screening of CHD on a mass level [30].

In Mohamed A. et al study the sensitivity of POS was $84 \%$ which is relatively similar to our study and the rate of false positive of POS was $0.17 \%$ [32] and this result is lower than our study because of large study sample in comparison to our study.
In Frank Th et al, the sensitivity of POS was 77, 78\% and positive predictive value was $25,93 \%$ and false positive rate of POS was $0.10 \%$ [32], which is relatively similar in comparison to our study.

In de Wahl Granelli A et al, showed that the POS sensitivity was $62 \%$ and false positive rate in detection of a major CHD was $0.17 \%$ [25]. The difference in this result is attributed to large study sample in comparison to our study, and most of their sample screened after 24 hour of life, which may lead to decrease the false positive rate in their study. However, there is a limited knowledge and cooperation from the local obstetrician to send for routine fetal echocardiography in our region, and also due to the patient's health education, therefore the percentage of CHD detected by prenatal ultrasound was $0 \%$ in the current study. In Wren et al the rate of antenatal detection of CHD was 20\% [2]. In Frank Th et al there was a relatively high percentage of $\mathrm{CHD}$ detected by prenatal ultrasound (60\%) [32].

The limitation in our study were that we could not followup all cases after discharge for later diagnosis of congenital heart diseases because of insufficient data recordings and insufficient man power.

Another limitation in this study, is that we did not check femoral pulses routinely; since half of the babies with duct dependent circulation detected at neonatal physical examination had poor or absent femoral pulsation as a major important warning sign so neglecting femoral pulses palpations is likely to reduce the detection of duct dependent circulation on clinical examination.

A strong point is relatively due to a large number was studied, pre-and post-ductal assessment of POS keeping POS results away from clinicians who performed physical examinations to reduce bias.

\section{CONCLUSION}

Current study shows that pulse oximetry screening of all well newborn babies in maternity and pediatric units is practically applicable with a minimum use of time, and it has significant improve in the detection of life threatening congenital heart disease at an early stage. A significant number of newborns babies in the current study was diagnosed with critical congenital heart defects whom have not been detected prenatally can be detected at an asymptomatic stage, before any clinical deterioration occurs. This makes it possible to avoid cardiogenic shock in these patients before hospital discharge. The low false positive rate, suggest that such screening will be cost effective. The important thing is probably to have one pulse oximetry screening during the first 24 hours of life to prevent circulatory collapse in hospital of babies with duct dependent pulmonary circulation and to perform a second pulse oximetry screening before discharging the newborn from nursery. Pulse oximetry screen performance for newborn is mainly a cost effective, because as each additional case that receives a timely diagnosis costs the same as the treatment of a child's readmittance in circulatory collapse, but there is probably an additional long term cost benefit from reduced neurological morbidity. 


\section{RECOMMENDATIONS}

This study recommends the followings:

1- Pulse oximetry screening should be achieved for following 3-6 hours of age. If an early discharge is planned. Therefore, screening test should be performed as late as possible.

2- Perform the screening in a quiet area in order to provide soothe and comfort atmosphere for the infant.

3- If it is possible, conduct screening while the infant is awake, quiet and calm.

4- Avoid to perform pulse oximetry screening on an infant, while he or she is sleeping, crying or cold due to oxygen saturations may be affected.

5- If you are using disposable pulse-oximetry probes, use only one clean probe for each screened infant. If reusable probes being applied, the probe should be cleaned according to manufacturer instruction prior to use. Because dirty probes are considered one of problems to decrease the reading accuracy and cause infection transmission.

6- Perform pulse oximetry on the right hand and one foot after 24 hours of age. Measurements should be taken in parallel or one after another. If an infant was born prematurely, screening will be performed when it is medically appropriate.

7- Ensure that all readings are accurate by using pulseoximetry equipment confidence indicators.

8- Follow up all cases with a positive POS after the discharge from hospital, because it is considered to be a great importance for later diagnosis of congenital heart diseases and provide sufficient recording data.

9- Perform examination of femoral pulses routinely.

\section{REFERENCE}

[1] D. Lloyd-Jones, R. Adams, M. Carnethon, G. De Simone, TB. Ferguson, K. Flegal, et al., "Heart disease and stroke statistics 2009 update: a report from the American Heart AssociationStatistics Committee and Stroke Statistics Subcommittee," Circulation, 119, pp. e21-181, 2009.

[2] C. Wren, Z. Reinhardt, K. Khawaja, "Twenty-year trends in diagnosis of life-threatening neonatal cardiovascuar malformations," Arch Dis Child Fetal Neonatal Ed, 93, pp. F33-5, 2008.

[3] R, Knowles, I, Griebsch, C, Dezateux, J, Brown, C. Bull, C. Wren, "Newborn screening for congenital heart defects: a systematic review and cost-effectiveness analysis," Health TechnolAssess, 9(44), pp. 115-18, 2005.

[4] JIE. Hoffman, S. Kaplan, "The incidence of congenital heart disease," J Am CollCardiol, 39, pp. 1890-900, 2002.

[5] C. Wren, S. Richmond, L. Donaldson, “Temporal variability in birth prevalence of cardiovascular malformations," Heart, 83, pp. 414-19, 2000.

[6] T. Tikanoja, "Effect of technical development on the apparent incidence of congenital heart disease," Pediatric Cardiol,16, pp. 100-1, 1995.

[7] [7] WT. Mahle, JW. Newburger, GP. Matherne, FC. Smith, TR. Hoke, R. Koppel, et al., "Role of pulse oximetry in examining newborns for congenital heart disease: a scientific statement from the AHA and AAP," Pediatrics, 124, pp. 823-36, 2009.

[8] SC. Mitchell, SB. Korones, HW. Berendes, "Congenital heart disease in 56,109 births incidence and natural history," Circulation, 43, pp. 323-32, 1971.

[9] KJ. Barrington, "Neonatal screening for life threatening congenital heart disease,” BMJ, 338, pp. 117-18, 2009.
[10] S. Richmond, G. Reay, M. Abu Harb, "Routine pulse oximetry in the asymptomatic newborn," Arch Dis Child Fetal Neonatal Ed, 87, pp. F83-8, 2002.

[11] M. Abu-Harb, E. Hey, C. Wren, "Death in infancy from unrecognized congenital heart disease," Arch Dis Child, 71, pp. 3-7, 1994.

[12] M. Mellander, J. Sunnegardh, "Failure to diagnose critical heart malformations in newborns before discharge: an increasing problem?,” ActaPaediatrica, 95, pp. 407-13, 2006.

[13] CPF. O’Donnell, COF. Kamlin, PG. Davis, JB. Carlin, CJ. Morley, "Clinical assessment of infant colour at delivery," Arch Dis Child Fetal Neonatal Ed, 92, pp. F465-7, 2007.

[14] WT. Mahle, "Physical examination and pulse oximetry in newborn infants: out with the old, in with the new?," $J$ Pediatrics, 152, p.. 747-8, 2008.

[15] P. Valmari, "Should pulse oximetry be used to screen for congenital heart disease?," Arch Dis Child Fetal Neonatal Ed, 92, pp. F219-24, 2007.

[16] B. Toth, A. Becker, B. Seelbach-Gobel, "Oxygen saturation in healthy newborn infants immediately after birth measured by pulse oximetry," Arch GynecolObstet, 266, pp. 105-7, 2002.

[17] AF. Bakr, HS. Habib, "Combining pulse oximetry and clinical examination in screening for congenital heart disease,” Pediatric Cardiol, 26, pp. 832-5, 2005.

[18] TR. Hoke, PK. Donohue, PK. Bawa, RD. Mitchell, A. Pathak, PC. Rowe, et al., "Oxygen saturation as a screening test for critical congenital heart disease: a preliminary study," Pediatric Cardiol, 23, pp. 403-9, 2002.

[19] RI. Koppel, C. Druschel, T. Carter, B. Goldberg, P. Mehta, R. Talwar, et al., "Effectiveness of pulse oximetry screening for congenital heart disease in asymptomatic newborns," Pediatrics, 111, pp. 451-5, 2003.

[20] J. Reich, S. Miller, B. Brogdon, J. Casatelli, T. Gompf, J. Huhta, et al., "The use of pulse oximetry to detect congenital heart disease,” J Pediatrics, 142, pp. 268-72, 2003.

[21] A. de Wahl Granelli, M. Mellander, J. Sunnegardh, K. Sandberg, I. Ostman-Smith, "Screening for ductdependant congenital heart disease with pulse oximetry: a critical evaluation of strategies to maximize sensitivity," ActaPaediatr, 94, pp. 1590-6, 2005.

[22] E. Rosati, G. Chitano, L. Dipaola, C. De Felice, G. Latini, "Indications and limitations for a neonatal pulse oximetry screening of critical congenital heart disease," $J$ Perinat Med, 33, pp. 455-7, 2005.

[23] DM. Sendelbach, GL. Jackson, SS. Lai, DE. Fixler, EK. Stehel, WD. Engle, "Pulse oximetry screening at 4 hours of age to detect critical congenital heart defects," Pediatrics, 122, pp. e815-20, 2008.

[24] A. Meberg, S. Brugmann-Pieper, D. Reidar, L. Eskedal, I. Fagerli, T Farstad, et al., "First day of life pulse oximetry screening to detect congenital heart defects," $J$ Pediatr, 152, pp. 761-5, 2008.

[25] A. de Wahl Granelli, M. Wennergren, K. Sandberg, M. Mellander, C. Bejlum, L. Inganas, et al., "Impact of pulse oximetry screening on detection of duct dependent congenital heart disease:a swedish prospective screening study in 39821 newborns,” BMJ, 338, pp. A3037, 2009.

[26] R. Arlettaz, A. Bauschatz, M. Mankhoff, B. Essers, U. Bauersfeld, "The contribution of pulse oximetry to the early detection of congenital heart disease in newborns," Eur J Pediatrics, 165, pp. 94-8, 2006.

[27] AR, Kanper, WT. Mable, GR. Martin, WC. Cooley, P. Komer, WR. Marrow, et al., "Stratigies for implimentation screening for critical congenetal heart disease,” pediatrics, 128, pp. C 1259. 2011.

[28] F. Riede, I. Dähnert, C. Woerner, A. Moeckel, N. Lorenz, M. Kabus, et al., "Reduction of the diagnostic gapin critical congenital Heart defects by Puls oxymetrie screening," Monatsschr Kinderheilkd, 157, pp. 896-902, 2009.

[29] A.F. BAKR and H.S. HABIB, "Combining pulse oximetry and clinical examination in screening for congenital heart disease," Pediatr Cardiol, 26, pp. 832-5, 2005.

[30] V. Balu, M. Gayathry, TH. Sinimol, R. Karimaserry, and K. Karukappilly, "Clinical Screening for Congenital Heart Disease 
at Birth: A Prospective Study in a Community Hospital in Kerala,” springer, 33, pp. 2Fs 13312-011, 2002.

[31] A. Mohamed, EL. Hatem, B. ALDeek, and B. Safiyaa, "Can Pulse Oximetry Screening Reduce the Postnatal Diagnostic Gap in Critical Congenital Heart Diseases?,” Med. J. Cairo Univ., 80, pp. 93-99, 2012.

[32] Th. Frank, W. Cornelia, D. Ingo, M. Andreas, K. Martin, S. Peter, "Effectiveness of neonatal pulse oximetry screening for detection of critical congenital heart disease in daily clinical routineresults from a prospective multicenter study,” J. Perinat. Med., 33, pp. 455-7, 2005 